\title{
Multispecies Laser Diagnostic System for Vehicle Tailpipe Emission Measurements
}

\author{
Luigi Biondo ${ }^{1}$, Oliver Diemel ${ }^{1}$, Vadim Doberstein ${ }^{1}$, Henrik Gerken ${ }^{1}$, Lars Illmann ${ }^{1}$, Michael Jonek ${ }^{1}$, \\ Marvin Schmidt ${ }^{1}$, Tim Steinhaus ${ }^{2}$, Steven Wagner ${ }^{1 *}$ \\ ${ }^{l}$ High Temperature Process Diagnostics, Institute for Reactive Flows and Diagnostics, Technische Universität Darmstadt, Germany \\ ${ }^{2}$ Institute for Internal Combustion Engines and Powertrain Systems, Technische Universität Darmstadt, Germany \\ * corresponding Author: wagner@ rsm.tu-darmstadt.de
}

\begin{abstract}
A multispecies in situ TDLAS-system for simultaneous detection of NO, $\mathrm{CO}, \mathrm{CO}_{2}, \mathrm{H}_{2} \mathrm{O}$ and $\mathrm{NH}_{3}$ was applied at an engine test rig for exhaust gas measurements and results were compared to commercially available reference systems.

OCIS codes: 120.1740 Combustion diagnostics; 120.4640 Optical instruments; 120.6200 Spectrometers and spectroscopic instrumentation
\end{abstract}

\section{Introduction}

Since the current political discussions on the environmental impact of motor vehicles and the continuing reduction of pollutant limits, pollutant emission from cars with internal combustion engines is a highly topical issue. In the development of internal combustion engines, the focus lies on the reduction of pollutant emission in order to comply with the limits set by the legislator.

Due to stricter pollutant emission limits, it is necessary to measure the regulated species at progressively lower levels. Important for evaluating exhaust emissions is the so-called cumulative emission. Here, the total mass amount of a pollutant is considered cumulatively over a given cycle. Thus, the cumulative emission of a vehicle which is leaving the exhaust system at the exhaust tailpipe is the value of interest. At present, the pollutant emission of a car is determined based on the standardized Worldwide Harmonized Light Vehicles Test Procedure (WLTP) [1], where the vehicle exhaust gases are measured while the car is driven on a chassis dynamometer. The applied measurement techniques are based on extractive principles which take samples and partially process them. The specifications of these techniques state a sampling rate in the range of a few $\mathrm{Hz}$. The low sampling rate in combination with the extractive measurement principle and gas treatment give rise to the assumption, that current portable emission measurement systems suffer from low-pass filter effects during transient engine operation and therefore achieve temporal resolutions which are greater than a second.

In the described work, results are presented, which were measured in situ, i.e. without gas sampling and without gas conditioning. The measurement technique used in this work is the Tunable Diode Laser Absorption Spectroscopy (TDLAS). The main advantage of this laser optical technique is its capability of contactless measurement without affecting the exhaust gas composition. Combined with high sensitivity and selectivity, simultaneous mole fraction measurement of multiple species can be realized with high temporal resolution ( 100 $\mathrm{Hz}$ ) and without the necessity for online-calibration. With this work, we investigate the temporal filtering effects of extractive techniques on the observed cumulative emission, caused by the suction and preparation procedures of the extractive measurement systems. These procedures consequently result in non-linearly low-pass filtered signals. In addition to the main combustion products $\mathrm{CO}_{2}$ and $\mathrm{H}_{2} \mathrm{O}-\mathrm{CO}, \mathrm{NO}$ and $\mathrm{NH}_{3}$ were measured simultaneously in the exhaust gas. The measuring cells were mounted directly at the tailpipe end, upstream of a commercially available reference PEMS. The acquired data were analyzed, and the measurements were compared to the reference system regarding the temporal resolution of transients in the species concentration, the cumulative emission and the absolute variation profile of the exhaust gas composition.

\section{Experimental Setup}

The sensor presented here is based on the TDLAS principle, which is explained in detail elsewhere [2]. Two measuring cells are used. The first one is conceptually based on a White cell with an absorption length of about 80 $\mathrm{cm}$ and an inner diameter of about $60 \mathrm{~mm}$. In this cell, $\mathrm{CO}$ and $\mathrm{NH}_{3}$ are detected by the time-multiplex method. The second cell combines the White principle with the possibility for two dual-pass channels. The White cell itself is used with an absorption length of about $73 \mathrm{~cm}$ for the detection of $\mathrm{NO}$, while the two dual-pass channels with an absorption length of approximately $11 \mathrm{~cm}$ serve for the detection of $\mathrm{H}_{2} \mathrm{O}$ and $\mathrm{CO}_{2}$. The sensor was applied at the engine test bench of the Institute for Internal Combustion Engines and Powertrain Systems (VKM) at TU Darmstadt. The engine, a three-cylinder Euro $6 \mathrm{~b}$ gasoline engine with a displacement volume of 1 liter and $88 \mathrm{~kW}$ of power, is 
installed in a test bench that allows to resemble various load profiles with a dynamometer (figure 1). The exhaust aftertreatment system (EAS) corresponds to that of a typical Euro 6 gasoline vehicle. The reference measuring system is the AVL M.O.V.E GAS PEMS iS [3].

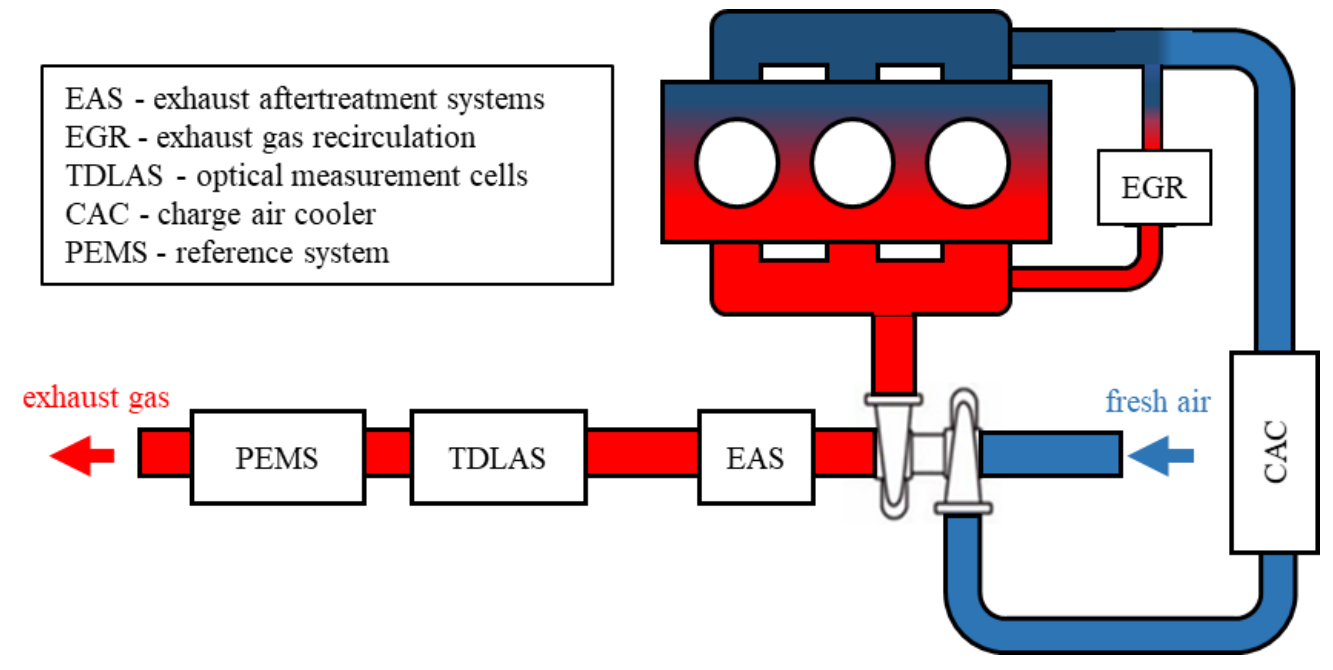

Fig. 1. System sketch of the experimental setup.

\section{Results and Discussion}

As an exemplary result, figure 2 shows a comparison between the reference system and the TDLAS system.

Presented is a 60 second window of the CO concentration during the Worldwide Harmonized Light Vehicles Test Cycle (WLTC). During periods of low transients (e.g. $20 \mathrm{~s}-30 \mathrm{~s}$ or $50 \mathrm{~s}-60 \mathrm{~s}$ ), the absolute values correspond well, whereas during large transients, the low-pass filter effect of the reference system becomes apparent. The peak value at $10 \mathrm{~s}$, for example, is underestimated by a factor of 2 by the reference system.

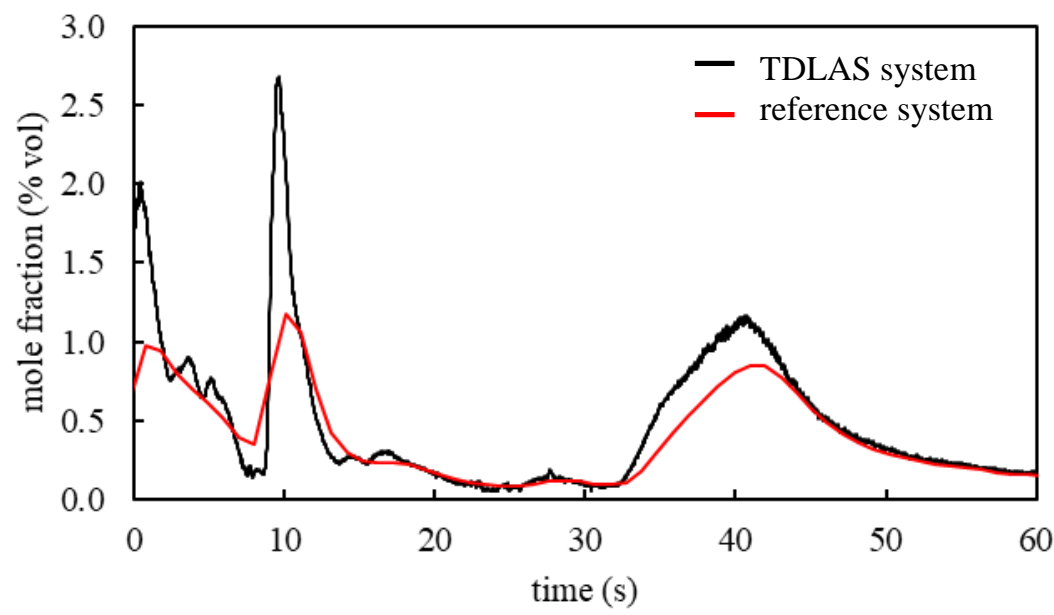

Fig. 2. Comparison of the CO concentration curve measured by the TDLAS system and the reference system.

\section{References}

[1] The European Commission, COMMISSION REGULATION (EU) 2016/427 of 10 March 2016 amending Regulation (EC) No 692/2008 as regards emissions from light passenger and commercial vehicles (Euro 6), 2016.

[2] Diemel, O. et al., "In situ sensor for cycle-resolved measurement of temperature and mole fractions in IC engine exhaust gases," Proceedings of the Combustion Institute, 2018, doi:10.1016/j.proci.2018.06.182.

[3] AVL List GmbH, AVL GAS PEMS IS - Product Guide, AT6103D Rev. 01, Graz, 2014. 